\title{
Acute Kidney Injury, CTCAE
}

National Cancer Institute

\section{Source}

National Cancer Institute. Acute Kidney Injury, CT CAE. NCI Thesaurus. Code C143262.

A disorder characterized by the acute loss of renal function (within 2 weeks) and is traditionally classified as pre-renal (low blood flow into kidney), renal (kidney damage) and post-renal causes (ureteral or bladder outflow obstruction). 